\title{
Base-Bleed Effect on X-33 Aerospike Plume Induced Base-Heating Environment During Power-Pack Out
}

\author{
Ten-See Wang ${ }^{*}$, Alan Droege ${ }^{\dagger}$, Mark D’Agostino $^{\ddagger}$, Young-Ching Lee ${ }^{\S}$, Robert Williams ${ }^{* *}$ \\ NASA Marshall Space Flight Center, Huntsville, AL 35812
}

\begin{abstract}
A computational heat transfer methodology was developed to study the dual-engine linear aerospike plume induced base-heating environment during one power-pack out, in ascent flight. One power-pack out results in reduction of power levels for both engines. That, in turn, reduces the amount of base-bleed and changes the distribution of base-bleed on the two pillows. Hence, the concern of increased base-heating during power-pack out. The thermo-flowfield of the entire vehicle was computed. The computational methodology for the convective heating is based on a three-dimensional, finite-volume, viscous, chemically reacting, and pressure-based computational fluid dynamics formulation. The computational methodology for the radiative heating is based on a three-dimensional, finite-volume, and spectral-line-based weighted-sum-of-gray-gases absorption computational radiation heat transfer formulation. A separate radiation model was used for diagnostic purposes. The computational methodology was systematically benchmarked. In this study, near-base radiative heat fluxes were computed and they compared well with those measured from an installed linear aerospike engine tests. The base-heating environment of 18 trajectory points selected from three power-pack out ascent scenarios was computed and is presented here.
\end{abstract}

Copyright (c) 2003 by the American Institute of Aeronautics and Astronautics, Inc. No copyright is asserted in the United States under Title 17, U.S. Code. The U.S. Government has a royalty-free license to exercise all rights under the copyright claimed herein for Government purposes. All other rights are reserved by the copyright owner.

- Staff, Applied Fluid Dynamics Analysis Group, Senior Member AIAA

${ }^{\dagger}$ Engineer, Applied Fluid Dynamics Analysis Group

₹ Team Lead, Fluid Physics and Dynamics Group

§.. Engineer, Fluid Physics and Dynamics Group

Team Lead, Applied Fluid Dynamics Analysis Group, Senior Member AIAA 
The power-pack out condition has the most impact on convective base-heating when it happens early in flight. The source of its impact comes from the asymmetric and reduced base-bleed.

\section{Nomenclature}

$\mathrm{C}_{1}, \mathrm{C}_{2}, \mathrm{C}_{3}, \mathrm{C}_{\mu}=$ turbulence modeling constants, $1.15,1.9,0.25$, and 0.09 .

$\mathrm{G} \quad=$ geometrical matrices

$\mathrm{H} \quad=$ total enthalpy

$\mathrm{h}=$ static enthalpy or altitude, $\mathrm{km}$

I $\quad=$ radiative intensity

$\mathrm{J}=$ Jacobian of coordinate transformation

$\mathrm{K}=$ forward rate constant

$\mathrm{k} \quad=$ turbulent kinetic energy

M = Mach number

$\mathrm{N}=$ total number of chemical species

$\mathrm{P} \quad=$ pressure

Pr $\quad=$ Prandtl number

$\mathrm{Q}=$ = heat flux, $\mathrm{kW} / \mathrm{m}^{2}$

$\mathrm{q}=1, \mathrm{u}, \mathrm{v}, \mathrm{w}, \mathrm{H}, \mathrm{k}, \varepsilon$, or $\rho_{\mathrm{i}}$

$\mathrm{R} \quad=$ recovery factor

$\mathrm{r} \quad=$ location coordinate

$\mathrm{S}_{\mathrm{q}} \quad=$ source term for equation $\mathrm{q}$

$\mathrm{T}^{+} \quad=$ law-of-the-wall temperature

$\mathrm{t}=$ time, $\mathrm{s}$ 


$$
\begin{array}{ll}
\mathrm{U} & =\text { volume-weighted contravariant velocity } \\
\mathrm{u}, \mathrm{v}, \mathrm{w} & =\text { mean velocities in three directions } \\
\mathrm{u}_{\tau} & =\text { wall friction velocity } \\
\mathrm{u}^{+} & =\text {law-of-the-wall velocity, }\left(\mathrm{u}_{\mathrm{u}} \mathrm{u}_{\tau}\right) \\
\mathrm{x}, \mathrm{y}, \mathrm{Z} & =\text { coordinate or distance } \\
\mathrm{y}^{+} & =\text {law-of-the-wall distance, }\left(\mathrm{y}_{\mathrm{p}} \mathrm{u}_{\tau} \rho / \mu\right) \\
\varepsilon & =\text { turbulent kinetic energy dissipation rate or wall emissivity } \\
\kappa & =\text { absorption coefficient } \\
\mu & =\text { effective viscosity, }\left(\mu_{1}+\mu_{\mathrm{t}}\right) \\
\xi & =\text { computational coordinates } \\
\Pi & =\text { turbulent kinetic energy production } \\
\rho & =\text { density } \\
\sigma_{\mathrm{q}} & =\text { turbulence modeling constants } \\
\varphi & =\text { energy dissipation function } \\
\omega & =\text { direction vector } \\
& =\text { chemical species production rate } \\
&
\end{array}
$$

Subscripts

$$
\begin{array}{ll}
\text { a } & =\text { ambient } \\
\mathrm{b} & =\text { black body or base } \\
\mathrm{c} & =\text { convective or center } \\
\mathrm{EA} & =\text { Engine A or "on" engine }
\end{array}
$$




$$
\begin{array}{ll}
\mathrm{EB} & =\text { Engine B or "off" engine } \\
\mathrm{l} & =\text { laminar flow } \\
\mathrm{p} & =\text { off-wall (wall function) point } \\
\mathrm{r} & =\text { radiative } \\
\mathrm{t} & =\text { turbulent flow } \\
\mathrm{W} & =\text { wall surface } \\
\infty & =\text { freestream } \\
0 & =\text { reference }
\end{array}
$$

\section{Introduction}

$\mathrm{X}-33$, a half-scale prototype of a proposed commercial, reusable launch vehicle (RLV), was designed to demonstrate new, reusable single-stage-to-orbit technologies. It was fueled by liquid hydrogen and liquid oxygen and featured a lifting body configuration coupled with two integrated, linear aerospike rocket engines. One goal of the project was to provide safe, reliable and affordable access to space.

It is well known that aerospike engines have the potential advantage of adjusting themselves to perform with maximum efficiency at all altitudes. ${ }^{1,2}$ However, the aerospike plume- induced, base-heating environments must be understood fully in order to satisfy safety and reliability requirements. One scenario of particular interest is the base-heating environment during a potential power-pack out (PPO) - the loss of one of the two integrated turbopump sets - resulting in reduced power levels for both engines. This in turn reduces the amount of base-bleed which protects the plug-base components such as the pillows and flex seals (see Fig. 1). The reduction of 
base-bleed during PPO is a concern in light of observed heat-induced flex seal damage, seen after a single-engine, hot-fire test at reduced power levels. Furthermore, the plumbing is such that for PPO operation the "on" engine-side of the pillow receives about $75 \%$ of the remaining basebleed, whereas only $25 \%$ goes to the "off" engine side. This creates a concern for the integrity of the plug-base components and the need to understand the physics and the impact of PPO on the ascent base-heating environment. Note that subscale testing is not useful since combustion effects such as radiative heating are not scalable. In addition, full scale testing is not feasible (since the risk of losing an engine is not acceptable) and cannot simulate altitude effect. Using anchored numerical tools to computationally simulate the base-heating environment during PPO is therefore a reasonable strategy to address these concern and needs.

In the following sections, the computational methodology and the benchmarks performed are delineated first. The PPO trajectory and the run matrix are then discussed. And finally, the computational results showing the effect of base-bleed on base-heating environment during PPO are presented.

\section{Solution Methodology}

\section{Computational Grid Generation}

Previous studies ${ }^{3,4}$ have shown that the $\mathrm{X}-33$ base-flowfield is three-dimensional due to the linear aerospike layout and the lifting body configuration. And, only half of the domain was computed since flow symmetry can be assumed in normal operating conditions. In those studies, the computational grid was gradually improved through a sequential grid-refinement technique to an eventual density of 2,217,444 points. $^{3}$ Under PPO situations the flow is asymmetric, hence the flow over the entire vehicle is solved. The grid density is hence doubled to $4,434,888$ points 
by mirror-imaging the original half-vehicle grid using software package GRIDGEN. ${ }^{5}$ Figure 1 shows a layout of the surface computational grid with component definitions. Notice the plugbase flex-seal region where severe base-heating is expected after PPO. An identical grid is used in the radiation calculation. The total grid-density is increased to $4,724,592$ points however, due to the accounting system in the radiation formulation.

\section{Flow and Radiation Computation}

The effect of base-bleed on the X-33 base-heating environment is investigated with two computational tools: the Finite-Difference Navier-Stokes (FDNS) CFD code ${ }^{6}$ for the convective heating and the General Radiation Solution Program (GRASP) ${ }^{7}$ for the radiative heating. These tools were developed at Marshall Space Flight Center (MSFC) and are continuously being improved by MSFC personnel and its supporting contractors. Systematic and rigorous benchmark studies have been performed for base flow and heat transfer applications. For example, FDNS has been validated for convective heat transfer inside rocket thrust chambers ${ }^{8}$ and coolant channels ${ }^{9}$, for base-pressure characterization of a four-engine clustered nozzle configuration, ${ }^{10,11}$ for Delta Clipper-Experimental (DC-X) base-drag induced by the engine exhaust during cold-flow and flight tests ${ }^{12}$, and for DC-X convective base-heat flux during landing $^{13}$. GRASP has been benchmarked for DC-X radiative base-heat flux during landing ${ }^{13}$. In this study, FDNS and GRASP calculations are conducted sequentially in order to save computational memory. The CFD computed pressure, $\mathrm{H}_{2} \mathrm{O}$ concentration, and temperature fields are inputs for the radiation calculations. The solution algorithm for the flow and radiation computation is summarized in the following. 


\section{Flow Solution and Convective Heat Transfer}

FDNS solves a general curvilinear coordinate, chemically reacting, viscous thermo-flowfield with Reynolds-averaged transport equations. A generalized form of these equations is given by

$$
\frac{\partial \rho q}{J \partial t}=\frac{\partial\left[-\rho U q+\left(\mu / \sigma_{q}\right) G(\partial q / \partial \xi)\right]}{\partial \xi}+\frac{S_{q}}{J}
$$

A pressure-based predictor-plus-multicorrector solution method is applied. ${ }^{14}$ The basic idea is to perform correction for the pressure and velocity fields by solving for a pressure correction so that the velocity-pressure coupling is enforced, based on the continuity constraint. A second-order central-difference scheme is employed to discretize the diffusion fluxes and source terms of the governing equations. For the convective terms, a second-order total-variation-diminishing difference scheme is used in this effort.

An extended $\mathrm{k}-\varepsilon$ turbulence model ${ }^{15}$ is used to describe the turbulence. $\mu_{\mathrm{t}}=\rho \mathrm{C}_{\mu} \mathrm{k}^{2} / \varepsilon$ is defined as the turbulence eddy viscosity. Turbulence modeling constants $\sigma_{\mathrm{q}}$ and source terms $\mathrm{S}_{\mathrm{q}}$ of the transport equations are given in Table 1. These turbulence modeling constants have been used extensively for combustion-driven and base flows ${ }^{8-14,16}$, while $\sigma_{\mathrm{k}}$ and $\sigma_{\varepsilon}$ are taken from the turbulence closure. ${ }^{15}$ A 7-species, 9-reaction detailed mechanism ${ }^{16}$ (Table 2) is used to describe the finite-rate hydrogen-oxygen afterburning chemical kinetics. The seven species are $\mathrm{H}_{2}, \mathrm{O}_{2}$, $\mathrm{H}_{2} \mathrm{O}, \mathrm{O}, \mathrm{H}, \mathrm{OH}$, and $\mathrm{N}_{2}$, where $\mathrm{H}_{2} \mathrm{O}$ is the major radiating medium. Although it has been shown that the importance of afterburning chemical kinetics diminishes at high altitudes during fullpower flight, ${ }^{3}$ the finite-rate chemistry is turned on for all the trajectory points in this study due to considerations of reduced power level and base-bleed during PPO. 
Table $1 \sigma_{\mathrm{q}}$ and $\mathrm{S}_{\mathrm{q}}$ of the transport equations

\begin{tabular}{ccc}
\hline \hline $\mathrm{q}$ & $\sigma_{\mathrm{q}}$ & $\mathrm{S}_{\mathrm{q}}$ \\
\hline 1 & 1.00 & 0 \\
$\mathrm{u}$ & 1.00 & $-\mathrm{P}_{\mathrm{x}}+\nabla\left[\mu\left(\mathrm{u}_{\mathrm{j}}\right)_{\mathrm{x}}\right]-(2 / 3)\left(\mu \nabla \mathrm{u}_{\mathrm{j}}\right)_{\mathrm{x}}$ \\
$\mathrm{v}$ & 1.00 & $-\mathrm{P}_{\mathrm{y}}+\nabla\left[\mu\left(\mathrm{u}_{\mathrm{j}}\right)_{\mathrm{y}}\right]-(2 / 3)\left(\mu \nabla \mathrm{u}_{\mathrm{j}}\right)_{\mathrm{y}}$ \\
$\mathrm{w}$ & 1.00 & $-\mathrm{P}_{\mathrm{z}}+\nabla\left[\mu\left(\mathrm{u}_{\mathrm{j}}\right)_{\mathrm{z}}\right]-(2 / 3)\left(\mu \nabla \mathrm{u}_{\mathrm{j}}\right)_{\mathrm{z}}$ \\
$\mathrm{H}$ & 0.90 & $\mathrm{DP} / \mathrm{DT}+\varphi$ \\
$\mathrm{k}$ & 0.89 & $\rho(\Pi-\varepsilon)$ \\
$\varepsilon$ & 1.15 & $\rho(\varepsilon / \mathrm{k})\left\{\left[\mathrm{C}_{1}+\mathrm{C}_{3}(\Pi / \varepsilon)\right] \Pi-\mathrm{C}_{2} \varepsilon\right\}$ \\
$\rho_{\mathrm{i}}$ & 0.90 & $\omega_{\mathrm{i}}, \mathrm{i}=1, \ldots, \mathrm{N}$ \\
\hline \hline
\end{tabular}

Table 2 Hydrogen/Oxygen combustion kinetics mechanism. $K_{f}=A^{B} \mathrm{e}^{-E / R T}$.

\begin{tabular}{cccc}
\hline Reaction & A & B & E/R \\
\hline $\mathrm{H}_{2}+\mathrm{O}_{2}=\mathrm{OH}+\mathrm{OH}$ & $1.700 \mathrm{E} 13$ & 0 & $2.407 \mathrm{E} 4$ \\
$\mathrm{OH}+\mathrm{H}_{2}=\mathrm{H}_{2} \mathrm{O}+\mathrm{H}$ & $2.190 \mathrm{E} 13$ & 0 & $2.590 \mathrm{E} 3$ \\
$\mathrm{OH}+\mathrm{OH}=\mathrm{O}+\mathrm{H}_{2} \mathrm{O}$ & $6.023 \mathrm{E} 12$ & 0 & $5.500 \mathrm{E} 2$ \\
$\mathrm{O}+\mathrm{H}_{2}=\mathrm{H}+\mathrm{OH}$ & $1.800 \mathrm{E} 10$ & 1.0 & $4.480 \mathrm{E} 3$ \\
$\mathrm{H}+\mathrm{O}_{2}=\mathrm{O}+\mathrm{OH}$ & $1.220 \mathrm{E} 17$ & -0.91 & $8.369 \mathrm{E} 3$ \\
$\mathrm{M}+\mathrm{O}+\mathrm{H}=\mathrm{OH}+\mathrm{M}$ & $1.000 \mathrm{E} 16$ & 0 & 0 \\
$\mathrm{M}+\mathrm{O}+\mathrm{O}=\mathrm{O}_{2}+\mathrm{M}$ & $2.550 \mathrm{E} 18$ & -1.0 & $5.939 \mathrm{E} 4$ \\
$\mathrm{M}+\mathrm{H}+\mathrm{H}=\mathrm{H}_{2}+\mathrm{M}$ & $5.000 \mathrm{E} 15$ & 0 & 0 \\
\hline
\end{tabular}




$$
\mathrm{M}+\mathrm{H}+\mathrm{OH}=\mathrm{H}_{2} \mathrm{O}+\mathrm{M} \quad 8.400 \mathrm{E} 21 \quad-2.0 \quad 0
$$

* M stands for third-body collision partner

A modified wall function approach is employed to provide wall boundary layer solutions that are less sensitive to the near-wall grid spacing. Consequently, the model has combined the advantages of both the integrated-to-the-wall approach and the conventional law-of-the-wall approach by incorporating a complete velocity profile ${ }^{17}$ given by

$$
\begin{aligned}
u+=\ln & {\left[\left(y^{+}+11\right)^{4.02} /\left(y^{+^{2}}-7.37 y^{+}+83.3\right)^{0.79}\right] } \\
& +5.63 \tan ^{-1}\left(0.12 y^{+}-0.441\right)-3.81
\end{aligned}
$$

and a universal temperature profile ${ }^{18}$ given by

$$
T^{+}=u^{+}+12.8\left(\operatorname{Pr}_{l}^{0.68}-1\right)
$$

The convective heat transfer from a hot boundary layer to a cooler wall follows the modified Newtonian law ${ }^{13}$

$$
\mathrm{Q}_{\mathrm{cw}}=\left(\rho \mathrm{u}_{\tau} / \mathrm{T}^{+}\right)\left[\mathrm{h}_{\mathrm{w}}-\mathrm{h}_{\mathrm{p}}-\mathrm{R}\left(\mathrm{u}_{\mathrm{p}}{ }^{2} / 2\right)\right]
$$

where $\mathrm{R}=\mathrm{Pr}_{1}{ }^{1 / 2}$ if $\mathrm{y}^{+} \leq 11.63$ and $\mathrm{R}=\mathrm{Pr}_{1}^{1 / 3}$ if $\mathrm{y}^{+}>11.63$, and $\mathrm{y}^{+}=11.63$ is the thickness of the viscous sublayer. A constant $\mathrm{Pr}_{1}$ of air is used in this study, since parametric studies performed in 
Ref. 13 show that the $\mathrm{H}_{2} / \mathrm{O}_{2}$ plume induced base heat flux is not sensitive to a multicomponent variable $\operatorname{Pr}_{1}$.

\section{Radiative Heat Transfer}

GRASP analyzes the radiative field by solving the general curvilinear coordinate radiative transfer equation with a finite-volume method (FVM) formulation: ${ }^{19}$

$(\Omega \cdot \nabla) I(r, \Omega)=-\kappa I(r, \Omega)+\kappa I_{b}(r)$

The term on the left-hand side represents the gradient of the intensity in the direction of $\Omega$. The two terms on the right-hand side represent the changes in intensity due to absorption and emission. The wall boundary is assumed gray while emitting and reflecting diffusely, and the radiative wall boundary condition is given by

$I\left(r_{w}, \Omega^{+}\right)=\varepsilon I_{b}\left(r_{w}\right)+\frac{(1-\varepsilon)}{\pi} \int_{n . \Omega^{-}<0} I\left(r_{w}, \Omega^{-}\right)\left|n . \Omega^{-}\right| d \Omega^{-}$

with

$q_{r w}=\int_{n \cdot \Omega^{-}<0} I\left(r_{w}, \Omega^{-}\right)\left|n \cdot \Omega^{-}\right| d \Omega^{-}$

where $\Omega^{+}$and $\Omega^{-}$denote the leaving and arriving radiative intensity directions, respectively. The 
20-band spectral-line weighted-sum-of-gray-gases model $^{7}$ is used to calculate the total emissivity and absorptivity of the radiating medium. Following the ray-dependency test performed in Ref. 13, the FVM $6 \times 4$ option - six control angles in the polar direction and four in the azimuthal direction - is deemed adequate and is used in this effort.

\section{Boundary and Initial Conditions}

The outer boundaries of the computational domain have the following conditions: the fixed total-condition (free-stream) and the flow exit plane. A no-slip wall is specified for the body surface. A fixed (ambient) static pressure is imposed on the exit plane and on a point far away from the action area (one grid point off the freestream boundary), in order to obtain a unique solution for the desired altitude. The fixed inlet boundary condition is applied to the exit plane of the 40 thrusters where the flow properties were obtained from a chemical equilibrium analysis using the $\mathrm{CEC}$ code. ${ }^{20}$

Base-bleed is accomplished in the actual engines by flowing a mixture of hydrogen gas and steam from thousands of orifices drilled on the pillows. Because it is computationally prohibitive to resolve all the individual orifices in the CFD model, the orifices and the pillow surface surrounding them can be lumped together and modeled as one base-bleed inlet boundary. In Ref 3 and 4, a fixed mass flow-rate (and energy) boundary condition is used in subsonic freestream cases and a fixed inlet boundary condition is applied in supersonic freestream cases. This approach however, precludes the calculation of convective heat flux on the pillow since it is treated as an inlet and not a wall. In this study, a special base-bleed boundary treatment is devised by combining the features of constant mass flow injection normal to the surface and those of wall boundary treatment such that the increased convective heating due to reduced base- 
bleed can be estimated for subsonic freestream cases. For supersonic freestream cases, the pillow convective heating is negligible and the fixed inlet boundary condition is retained. The basic assumptions for the base-bleed boundary treatment are that the injection is always normal to the wall surface and the mass flow rate specified is constant throughout the computation. Constant injection temperature and species composition are imposed to maintain a fixed inlet enthalpy. Since the base-bleed boundary is treated partially as a wall, the wall function approach is applied and the wall heat flux can be estimated. Figure 2 shows the computed base-bleed flow vectors at $40 \mathrm{~s}$ into the PPO at launch $+30 \mathrm{~s}$ trajectory. Note that the flow vectors (mass flow rate) of the "off" engine side are about $1 / 3$ the length of those of the "on' engine side.

For convective heat transfer calculations, ambient temperature is prescribed as the forebody and aftbody surface temperatures, whereas $540 \mathrm{deg} R$ is specified for all base surfaces per baseheating design convention. For radiation calculations, the surface emissivity of the entire vehicle is assumed to be $0.7 .^{13}$ The engine ramp is actively cooled and the surface temperature distribution is prescribed from a separate conjugate heat transfer calculation involving solid walls and coolant channel flows. It was found ${ }^{3}$ that cowl-base irradiation is more than ten times higher if an adiabatic condition is imposed on the ramp surface. Hence, a more accurate boundary condition is employed. Notice that the effect of re-irradiation from surface radiation is included in all calculations.

\section{X-33 Specific Computational Benchmarks Performed}

\section{Forebody and Aftbody Surface Pressure Coefficients}

The X-33 forebody and aftbody surface pressure coefficients were computed and compared reasonably well with those of a $7.75 \%$ scaled model cold-flow test. ${ }^{3}$ These comparisons indicate 
that the incoming flow environment is adequately simulated for $\mathrm{X}-33$ base-flow development.

\section{Installed Linear Aerospike Engine Plume Induced Noise}

The X-33 CFD plume data base ${ }^{3}$ was used in conjunction with an engineering acoustic radiation model to predict the acoustic environment ${ }^{21}$ of the linear aerospike engine, with that measured from a series of hot fire tests. The predicted far-field acoustic spectra, directivity pattern, and overall sound pressure levels agreed reasonably well with those of measurement. Since the acoustic radiation model uses CFD computed $(\partial \mathrm{u} / \partial \mathrm{n})^{-1},(\mathrm{k} / \varepsilon)$, and $(\mathrm{k} \rho / \varphi)$ for time scaling, this benchmark indicates the CFD computed X-33 plume velocity and turbulence fields are adequate.

\section{$\underline{\text { Base-Pressure Characteristic curves }}$}

The base-pressure characteristic curve is the central base-pressure plotted as a function of ambient pressures. The computed base-pressure characteristic curve was compared with that of a $7.75 \%$ scaled model cold flow test ${ }^{3}$ and that of a $2.25 \%$ scaled model hot flow test. ${ }^{4}$ The reasonable agreement indicates that the predicted base-pressure characteristic curve is adequate.

\section{Sea-Level Base Pillow pressures}

The computed sea-level base pillow pressures agreed reasonably well with those of a $2.25 \%$

scaled model hot-flow test. ${ }^{4}$ The predicted and measured ${ }^{22}$ pressure levels indicate there is a strong aspiration occurring on the base pillow at low altitudes. 


\section{Base Horizontal Centerline Convective Heat Fluxes}

Base horizontal centerline convective heat fluxes were computed and compared with those of a $2.25 \%$ scaled model hot-flow test at sea level, at $23.4 \mathrm{~km}$, and at $23.4 \mathrm{~km}$ with fences installed. ${ }^{4}$ The measurements ${ }^{22}$ were made on the plug-base, side wall, inner-base, offset outer-base and outer-base. Not only is the predicted convective base heating in good agreement with experimental data, the linear aerospike base-heating physics such as the formation of the reverse jet, lateral wall jet, plume spillage, and aspiration jet are well captured.

\section{Installed Linear Aerospike Engine Plume Induced Base Radiative Heat Fluxes}

In this study, near base radiative heat fluxes were computed and compared with those measured from a series of hot fire tests of a single X-33 XRS-2200 linear aerospike engine at the NASA Stennis Space Center in 1999 and 2000. Wide band plume radiation data were collected. Plume radiation instrumentation consisted of several $180^{\circ}$ hemispherical radiometers. A typical view of the engine and plume during test is shown in figure 3.

Wide-angle (180 deg.) radiometer locations were selected to provide orientations similar to that of flight vehicle surfaces and flight test instruments. Most instruments (e.g., radiometer R101B, see Fig. 4) were located to the side parallel to the engine long axis in what would be the engine base region. One radiometer (R105, see Fig. 5) was in close proximity to the engine near the cowl base and thruster area on the ramp side.

Radiation predictions were made using FDNS flow field solutions with heating rates generated by the GASRAD code. The GASRAD code uses a statistical band model for exponential line strength distribution with Lorentz/Doppler line shapes for gaseous species. Its geometry model provides high fidleity integration over a hemisphere and can accept either 
axisymmetric or three dimensional plumes. GASRAD is particularly well suited for very accurately predicting radiation to indiviual geometry points, while GRASP is typically used for entire surface predictions due to its relatively high computational efficiency. Details of the GASRAD radiation formulations can be found in Ref. 23.

An FDNS solution was generated at sea level ambient pressure. Ground test radiation data are compared to sea level predictions in figures 4 and 5. Predicted levels agreed quite well with measured data. Temporal variation of the data is due to engine startup and shutdown transients, as well as scheduled power level and fuel mixture ratio changes.

Some additional insight into modeling accuracy can also be gained from these data. Radiometer R101B has a view factor encompassing a large potion of the engine plume. The fact that the predicted level agrees well with the data as shown in figure 4 gives us confidence that the overall plume flow field is being modeled accurately. Figure 5 shows that data from the cowl base region radiometer (R105) is also predicted accurately. This indicates that the local flow field just downstream of the engine thrusters is being accurately modeled because the field of view of R105 is predominant in this region. The results of these benchmarks validate our computational heat transfer model for studying the X-33 aerospike plume induced base-heating environment during PPO.

\section{PPO Trajectories and Run Matrix}

The linear aerospike plume-induced X-33 base-heating environment was computed for trajectory points selected from three PPO scenarios: $\mathrm{PPO}$ at Launch $(\mathrm{L})+30 \mathrm{~s}, \mathrm{PPO}$ at $\mathrm{L}+60 \mathrm{~s}$, and PPO at $\mathrm{L}$ +120 s. The ascent mission was expected to fail if PPO occurs before $L+30 \mathrm{~s}$. Figure 6 shows the computational points selected on the thrust, altitude, and Mach number profiles for those three PPO 
trajectories. Six strategic points were selected for each trajectory in order to bracket the baseheating environment. Note that one point was chosen before the PPO and another point was chosen after the PPO. This is best illustrated in thrust profiles since the biggest power difference occurred right after the PPO. To save computational time, several selected points were overlapped on the three PPO trajectories. For example, the trajectory points of 0 and $30 \mathrm{~s}$ on the PPO at $\mathrm{L}+60 \mathrm{~s}$ trajectory are identical to those of 0 and $30 \mathrm{~s}$ on the PPO at $\mathrm{L}+30 \mathrm{~s}$ trajectory. This way, the original number of computational points of 18 is reduced to 13 . The power levels of the dual engines at selected trajectory points were provided. The base-bleed mass flow rates on the two pillows were calculated based on the $75 / 25$ split for engine-off cases. Tables 3-5 show the run matrix for the three PPO trajectories.

Table 3 Run matrix for PPO @ L+30 s trajectory

\begin{tabular}{|c|r|r|r|r|r|r|r|r|r|}
\hline Case & $\mathrm{t}, \mathrm{s}$ & $\mathrm{M}_{\infty}$ & $\mathrm{H}, \mathrm{ft}$ & $\mathrm{PL}_{\mathrm{EA}}$ & $\mathrm{PL}_{\mathrm{EB}}$ & $\mathrm{O} / \mathrm{F}_{\mathrm{EA}}$ & $\mathrm{O} / \mathrm{F}_{\mathrm{EB}}$ & $\dot{m}_{b b, E A}$ & $\dot{m}_{b b, E B}$ \\
\hline 1 & 0 & 0.00 & 0 & 0.8187 & 0.7971 & 5.7225 & 5.4298 & 9.930 & 9.666 \\
\hline 2 & 30 & 0.44 & 9495 & 0.9958 & 1.0023 & 5.6546 & 5.6489 & 12.088 & 12.168 \\
\hline 3 & 40 & 0.37 & 13821 & 0.4937 & 0.4827 & 5.7224 & 5.4032 & 8.995 & 2.919 \\
\hline 4 & 100 & 0.21 & 28954 & 0.4992 & 0.4904 & 5.5420 & 5.6735 & 9.119 & 2.959 \\
\hline 5 & 200 & 1.39 & 77217 & 0.5109 & 0.4817 & 5.6897 & 5.7159 & 9.147 & 2.968 \\
\hline 6 & 280 & 5.00 & 168498 & 0.4571 & 0.4043 & 6.1580 & 5.8515 & 7.918 & 2.570 \\
\hline
\end{tabular}

Table 4 Run matrix for PPO @ L+60 s trajectory

\begin{tabular}{|l|l|l|l|l|l|l|l|l|l|}
\hline Case & $\mathrm{t}, \mathrm{s}$ & $\mathrm{M}_{\infty}$ & $\mathrm{H}, \mathrm{ft}$ & $\mathrm{PL}_{\mathrm{EA}}$ & $\mathrm{PL}_{\mathrm{EB}}$ & $\mathrm{O} / \mathrm{F}_{\mathrm{EA}}$ & $\mathrm{O} / \mathrm{F}_{\mathrm{EB}}$ & $\dot{m}_{b b, E A}$ & $\dot{m}_{b b, E B}$ \\
\hline
\end{tabular}




\begin{tabular}{|c|r|r|r|r|r|r|r|r|r|}
\hline 1 & 0 & 0.00 & 0 & 0.8187 & 0.7971 & 5.7225 & 5.4298 & 9.930 & 9.666 \\
\hline 2 & 30 & 0.44 & 9495 & 0.9958 & 1.0023 & 5.6546 & 5.6489 & 12.088 & 12.168 \\
\hline 3 & 60 & 0.74 & 28904 & 0.7200 & 0.7449 & 5.6331 & 5.7783 & 8.7262 & 9.0297 \\
\hline 4 & 61 & 0.74 & 29716 & 0.3780 & 0.3984 & 4.6746 & 4.9030 & 7.0679 & 2.2936 \\
\hline 5 & 200 & 3.49 & 130321 & 0.5023 & 0.4854 & 5.3726 & 5.7644 & 9.0121 & 2.9244 \\
\hline 6 & 270 & 7.28 & 166925 & 0.4277 & 0.4161 & 5.4451 & 5.6719 & 7.6884 & 2.4949 \\
\hline
\end{tabular}

Table 5 Run matrix for PPO @ L+120 s trajectory

\begin{tabular}{|c|r|r|r|r|r|r|r|r|r|}
\hline Case & \multicolumn{1}{c|}{$\mathrm{t}, \mathrm{s}$} & $\mathrm{M}_{\infty}$ & $\mathrm{H}, \mathrm{ft}$ & $\mathrm{PL}_{\mathrm{EA}}$ & $\mathrm{PL}_{\mathrm{EB}}$ & $\mathrm{O} / \mathrm{F}_{\mathrm{EA}}$ & $\mathrm{O} / \mathrm{F}_{\mathrm{EB}}$ & $\dot{m}_{b b, E A}$ & $\dot{m}_{b b, E B}$ \\
\hline 1 & 0 & 0.00 & 0 & 0.8187 & 0.7971 & 5.7225 & 5.4298 & 9.930 & 9.666 \\
\hline 2 & 30 & 0.44 & 9495 & 0.9958 & 1.0023 & 5.6546 & 5.6489 & 12.088 & 12.168 \\
\hline 3 & 60 & 0.74 & 28904 & 0.7200 & 0.7449 & 5.6331 & 5.7783 & 8.7262 & 9.0297 \\
\hline 4 & 120 & 2.10 & 86219 & 0.6989 & 0.7050 & 5.3333 & 5.4306 & 8.4689 & 8.5433 \\
\hline 5 & 121 & 2.13 & 87422 & 0.3857 & 0.3944 & 4.6381 & 4.7817 & 7.1029 & 2.3049 \\
\hline 6 & 240 & 7.61 & 157609 & 0.4549 & 0.4068 & 6.0918 & 5.9687 & 7.8571 & 2.5487 \\
\hline
\end{tabular}

\section{Results and Discussion}

The flow computations were performed on a NASA MSFC Silicon Graphics Power Challenge cluster using 8 processors. The computational time for a typical calculation is $4.5 \times 10^{-5} \mathrm{CPU}$ s/grid/step/processor. Usually, 2000-6000 iterations are required to achieve an approximate convergence. The radiation computations were performed on a NASA AMES Silicon Graphics 
Origin 2000 cluster using 16 processors. The computational time for a typical run is $5.0 \times 10^{-5} \mathrm{CPU}$ s/grid/step/direction/processor. In general, 20-40 iterations are used to achieve an approximately converged solution.

Figures 7 shows the computed convective heat flux contours for the $30 \mathrm{~s}$ and $40 \mathrm{~s}$ trajectory points on the PPO at launch $+30 \mathrm{~s}$ trajectory. Different color scales are used for the plug base, the engine ramp, and the rest of the body surface such that the base-heating physics can be revealed. Unique three-dimensional base heat-flux contours are formed for each trajectory point due to the interaction of the reverse jet and the lateral wall jet with the pillowed plug base and the base-bleed. Contrasting to the approximately symmetric heat flux contours at $30 \mathrm{~s}$ (before PPO), the asymmetric heating pattern after PPO can be seen clearly at the $40 \mathrm{~s}$ heat flux contours, where the convective heat fluxes are much higher on the plug-base pillow and flex seals of the off-engine side (the right-hand side) than those of the on-engine side (the left-hand side), although the power level at $40 \mathrm{~s}$ is about half as that at $30 \mathrm{~s}$. It is postulated that this asymmetric heating is caused by the reduced and asymmetric base-bleed and possibly a longer residence time for afterburning (due to reduced power level and reduced free stream Mach number). The convective heating decreases with time and becomes negligible at $200 \mathrm{~s}$ and $280 \mathrm{~s}$ due to a weak reverse jet weakened by the reduced power level and the high altitude plume attenuation (not shown). As a result of the reduced power level, there is negligible lateral plume jet impingement heating on the outer- and offset outerbases at high altitudes, when compared with that computed at the full-power level. ${ }^{3}$ A similar phenomenon occurs at the $60 \mathrm{~s}$ (before PPO) and $61 \mathrm{~s}$ (after PPO) for the PPO at launch $+60 \mathrm{~s}$ trajectory. For PPO at launch $+120 \mathrm{~s}$ trajectory, it appears that the PPO imposes negligible effect on base-heating due to low power level and high altitude.

Figures 8 shows the computed radiative heat flux contours for the $30 \mathrm{~s}$ and $40 \mathrm{~s}$ trajectory points 
on the PPO at launch $+30 \mathrm{~s}$ trajectory. The radiative heating is transported through "view factors", whereas the convective heating is transported through direct contact of the propulsive flow with the solid surface. Hence, the computed radiative heat flux contours look very different from those of the convection. For example, the upper and lower portions of the inner and outer bases show effect of radiative heating but not the middle section, since the nozzle plug blocks the radiation from the upper and lower plumes. In general, it is found that the computed radiative heat flux after PPO is lower than that before PPO. That is, the effect of reduced power level on radiative heat flux is bigger than that of the reduced base-bleed.

Figures 9 shows computed two-dimensional centerline convective heat fluxes versus wetted distance in the horizontal direction on the various base surfaces of interest for the three PPO scenarios. For clarity, only those at selected trajectory points (before and after PPO) are shown, while the centerline heat flux at $0 \mathrm{~s}$ is shown as a baseline for comparison. It can be seen from Fig. 9, for the PPO at launch $+30 \mathrm{~s}$ trajectory, that although the engine power level (PL) is reduced to about $50 \%$ due to the PPO event, the peak convective heating on the off-engine side plug-base at 40 $\mathrm{s}$ is much higher (and closer to the middle) than that at $30 \mathrm{~s}$ and $100 \%$ PL, caused by an uneven split of the reduced base-bleed that sends only $2.919 \mathrm{lb} / \mathrm{s}$ to the off-engine side and $8.995 \mathrm{lb} / \mathrm{s}$ to the on-engine side. In fact, the convective heating is higher than that at sea level $(0 \mathrm{~s})$, which in turn is higher than that at $30 \mathrm{~s}$. At a later time (not shown), e.g., at $100 \mathrm{~s}$, although there is still asymmetric heating on the plug-base, the absolute magnitude of the heating is less than that prior to the PPO, due to higher plume attenuation. At $200 \mathrm{~s}$ and $280 \mathrm{~s}$, the plume expansion is too strong to numerically stabilize the special base-bleed boundary condition and a fixed inlet has to be used. It can be safely assumed that the convective heating at those altitudes is negligible based on the results from other base surfaces. At $61 \mathrm{~s}(1 \mathrm{~s}$ after PPO) of the PPO at launch $+60 \mathrm{~s}$ trajectory, 
there is asymmetric heating and the heating levels are higher than those of the $60 \mathrm{~s}$ (before PPO) on both on- and off-engine side. The heating level at $60 \mathrm{~s}$ is already low due to already reduced power level. Therefore, the heating level at $61 \mathrm{~s}$ is lower than that at $0 \mathrm{~s}$ and $30 \mathrm{~s}$. Hence, it is determined that PPO has negligible impact on plug-base at PPO +60 s trajectory. Similarly, it is concluded that $\mathrm{PPO}$ has negligible impact on plug-base heating to the $\mathrm{PPO}+120 \mathrm{~s}$ trajectory as well.

Figure 10 shows the effect of PPO on the lower flex seal horizontal centerline convective heat fluxes for the three PPO scenarios. The heating profiles for the upper and lower seals are slightly different due to the asymmetry of the upper and lower geometries of the X-33 vehicle. The heating levels for the two seals are very similar, so only those on the lower seals are discussed. It can be seen that the curves in PPO at $30 \mathrm{~s}$ trajectory have distinctive peaks at the center, caused by the strong wall jet formed by the reverse jet impingement between the pillows. This strong wall jet has no place to go but upwards (toward the upper flex seal) and downwards (toward the lower flex seal), where it is then swiped away by the propulsive flow to form the double triangle recirculation pattern. ${ }^{4}$ The two "wings" on both sides of the central heating curve are caused by the wall jet formed by the reverse jet on the pillows, which swirls down the pillow and flows through the seal region. The central heating level of the $30 \mathrm{~s}$ curve is higher then that of the $0 \mathrm{~s}$ (due to higher engine power level), but its "wing" heating is flattened out and lower than that of the $0 \mathrm{~s}$ (due to higher altitude and more base-bleed). At $40 \mathrm{~s}$, although the central heating level is less than that of the $30 \mathrm{~s}$ (due to reduced power level during PPO), its "wing' heating level is higher and closer to the center (due to reduced base-bleed); and it is higher at the "off" engine side (due to the 75/25 split). The curve at $61 \mathrm{~s}$ (after PPO) is higher than that at $60 \mathrm{~s}$ (before PPO) in PPO at L $+60 \mathrm{~s}$ trajectory. The curves in the PPO at $120 \mathrm{~s}$ trajectory are both low and the effect of PPO is negligible. The heating for the PPO at launch $+60 \mathrm{~s}$ and PPO at launch $+120 \mathrm{~s}$ trajectories is less 
than that at launch $+30 \mathrm{~s}$ since base convective heating is less significant at higher altitudes.

Figures 11 and 12 show radiative heat fluxes similar to those shown in Fig's 9-10 for convective heat fluxes for the three PPO trajectories. In addition to the view factor, the radiative heating levels are also functions of power level, altitude, base-bleed, and free-stream Mach number. Of all the cases studied, the radiative heating after PPO is mostly lower than that seen before PPO on all base surfaces. This is particularly true for the radiative heating on the flex seals. As altitude or PPO time increases, the radiative heating decreases. Note that the level of radiative heating is quite different from that of convective heating on various components. For example, the peak level of radiative heating (Fig. 11) on the base horizontal centerline for PPO at launch $+30 \mathrm{~s}$ trajectory is about twice as that of convective heating (Fig. 9), whereas the peak heating levels on flex seals for both (Fig's 10 and 12) are about the same. Again, the PPO has no effect on the PPO at L $+120 \mathrm{~s}$ trajectory since the heating level before PPO is already negligible.

\section{Conclusions}

A computational heat transfer analysis was performed to study the linear aerospike plume induced base-heating environment during PPO in ascent flight. Eighteen trajectory points selected from three PPO ascent scenarios were computed. The results are presented as three-dimensional convective and radiative heat flux contours and two-dimensional convective and radiative heat flux profiles versus wetted distance on component surfaces of interest. The base-heating environment during PPO is enveloped and the dual-engine base-heating physics during PPO is illustrated. In general, the locations that endure the most severe heating before and after PPO are the center of the flex seal and the center of the plug-base. PPO alters convective base-heating most when it occurs in the earliest scenario (PPO at launch +30 s trajectory). The source of the impact of PPO on base- 
heating comes from the asymmetric and reduced base-bleed.

\section{Acknowledgments}

John Sutter and Charlie Dill of X-33 Program Office supported this effort. The X-33 Program Office also provided partial support for Drs. Y.-S., Chen and J.-W. Liu of Engineering Sciences, Inc. for implementing the latest upgrades to the FDNS and GRASP codes. Stan Douglas of Mechanical System Control Group provided basic trajectory information. The lead author also wishes to thank Robert Garcia for reading the manuscript.

\section{References}

${ }^{1}$ Tomita, T., Takahashi, M., Onodera, T., and Tamura, H., "A Simple Performance Prediction Model of Clustered Linear Aerospike Nozzles,” AIAA Paper 2001-3560, July 2001.

${ }^{2}$ Huang, D.H., "Aerospike Engine Technology Demonstration for Space Propulsion," AIAA Paper 74-1080, Oct. 1974.

${ }^{3}$ Wang, T.-S., "Analysis of Linear Aerospike Plume Induced X-33 Base-Heating Environment," Journal of Spacecraft and Rockets, Vol. 36, No. 6, Nov.-Dec., 1999, pp. 777-783.

${ }^{4}$ Wang, T.-S., "Effect of Fence on Linear Aerospike Plume Induced Base-Heating Physics," Journal of Thermophysics and Heat Transfer, Vol. 14, No. 4, October-December, 2000, pp. 457463.

${ }^{5}$ Steinbrenner, J.P., Chawner, J.R., and Fouts, C., "Multiple Block Grid Generation in the interactive Environment," AIAA Paper 90-1602, June 1990.

${ }^{6}$ Anon, "Injector Design Tool Improvements - Final Technical Report and User's manual for FDNS V.4.5," Engineering Sciences, Inc., ESI-TR-98-02, Huntsville, AL, April 1998. 
${ }^{7}$ Liu, J., Shang, H.-M., Chen, Y.-S., and Wang, T.-S., “GRASP: A general Radiation Simulation Program,” AIAA Paper 97-2559, June, 1997.

${ }^{8}$ Wang, T.-S., and Luong, V., "Hot-Gas-Side and Coolant-Side Heat Transfer in Liquid Rocket Engine Combustors," Journal of Thermophysics and Heat Transfer, Vol. 8, No. 3, 1994, pp. 524530.

${ }^{9}$ Wang, T.-S., and Chyu, M.K., "Heat Convection in a 180 -Deg Turning Duct with Different Turn Configurations," Journal of Thermophysics and Heat Transfer, Vol. 8, No. 3, 1994, pp. 596-601.

${ }^{10}$ Wang, T.-S., "Numerical Analysis of Base Flowfield for a Four-Engine Clustered Nozzle Configuration," Journal of Propulsion and Power, Vol. 11, No. 5, 1995, pp. 1076-1078.

${ }^{11}$ Wang, T.-S., "Grid-Resolved Analysis of Base Flowfield for Four-Engine Clustered Nozzle Configuration," Journal of Spacecraft and Rockets, Vol. 33, No. 1, 1996, pp. 22-29.

${ }^{12}$ Wang, T.-S., and Cornelison, J., "Analysis of Flowfields over Four-Engine DC-X Rockets," Journal of Spacecraft and Rockets, Vol. 34, No. 5, 1997, pp. 620-627.

${ }^{13}$ Wang, T.-S., "Delta Clipper-Experimental In-Ground Effect on Base-Heating Environment," Journal of Thermophysics and Heat Transfer, Vol. 12, No. 2, 1998.

${ }^{14}$ Wang, T.-S., and Chen, Y.-S., "Unified Navier-Stokes Flowfield and Performance Analysis of Liquid Rocket Engines," Journal of Propulsion and Power, Vol. 9, No. 5, 1993, pp. 678-685.

${ }^{15}$ Chen, Y.-S., and Kim, S. W., "Computation of Turbulent Flows Using an Extended k- $\varepsilon$ Turbulence Closure Model," NASA CR-179204, Oct. 1987.

16 Wang, T.-S., McConnaughey, P., Chen, Y.-S., and Warsi, S., "Computational Pollutant Environment Assessment from Propulsion System Testing," Journal of Spacecraft and Rockets, Vol. 33, No. 3, 1996, pp. 386-392. 
${ }^{17}$ Liakopolous, A., "Explicit Representations of the Complete Velocity Profile in a Turbulent Boundary Layer," AIAA Journal, Vol. 22, No. 6, 1984, pp. 844-846.

${ }^{18}$ White, F.M., Viscous Fluid Flow, McGraw-Hill, New York, 1974, pp. 562-563.

${ }^{19}$ Liu, J., Shang, H.-M., Chen, Y.-S., and Wang, T.-S., "Prediction of Radiative Transfer in General Body-Fitted Coordinates," Numerical Heat Transfer, Part B, Vol. 31, 1997, pp. 423-439. 20 Svehla, R.A., and McBride, B.J., "FORTRAN IV Computer Program for Calculation of Thermodynamic and Transport Properties of Complex Chemical Systems," NASA TN D-7056, Jan. 1973.

${ }^{21}$ Frendi, A., Nesman, T., and Wang, T.-S., "Computational and Experimental Study of Linear Aerospike Engine Noise,” AIAA Journal, Vol. 39, No. 8, August 2001, pp. 1485-1492.

${ }^{22}$ Engel, C.D., Bender, R.L., Engel, B.A., Sebghati, J.M., NASA SBIR 95-1 Phase II Aerospike Plug Base Heating Model Development Final Report, QTR 017-012, Qualis Corporation, Huntsville, AL, Dec. 31, 1998.

${ }^{23}$ Reardon, J., and Lee, Y.-C., "A Computer Program for Thermal Radiation from Gaseous Rocket Plumes (GASRAD),” Report RTR 014-9, REMTech, Inc., Huntsville, AL, Dec. 1979. 


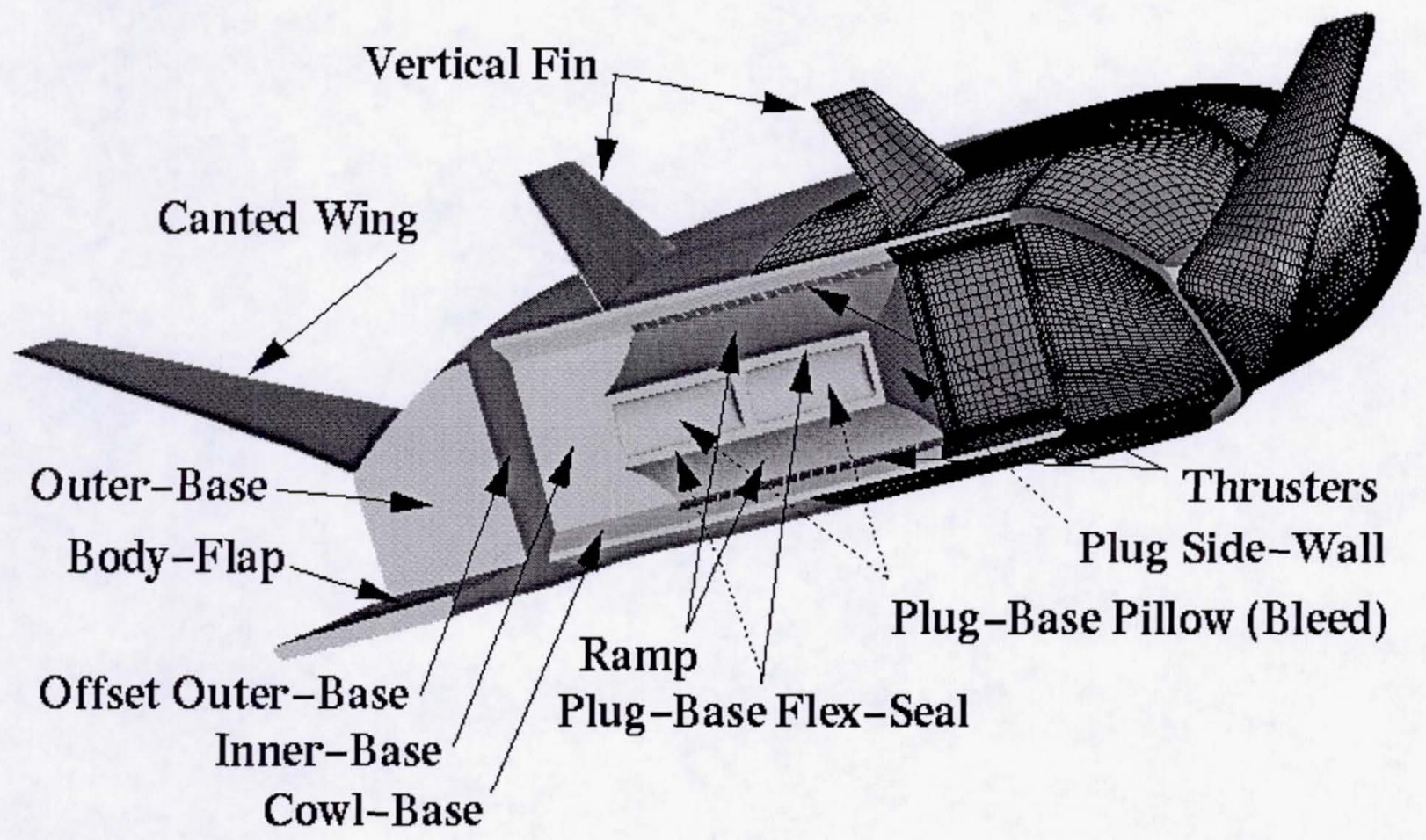

Fig. 1 Layout of an X-33 surface computational grid with component definitions. 


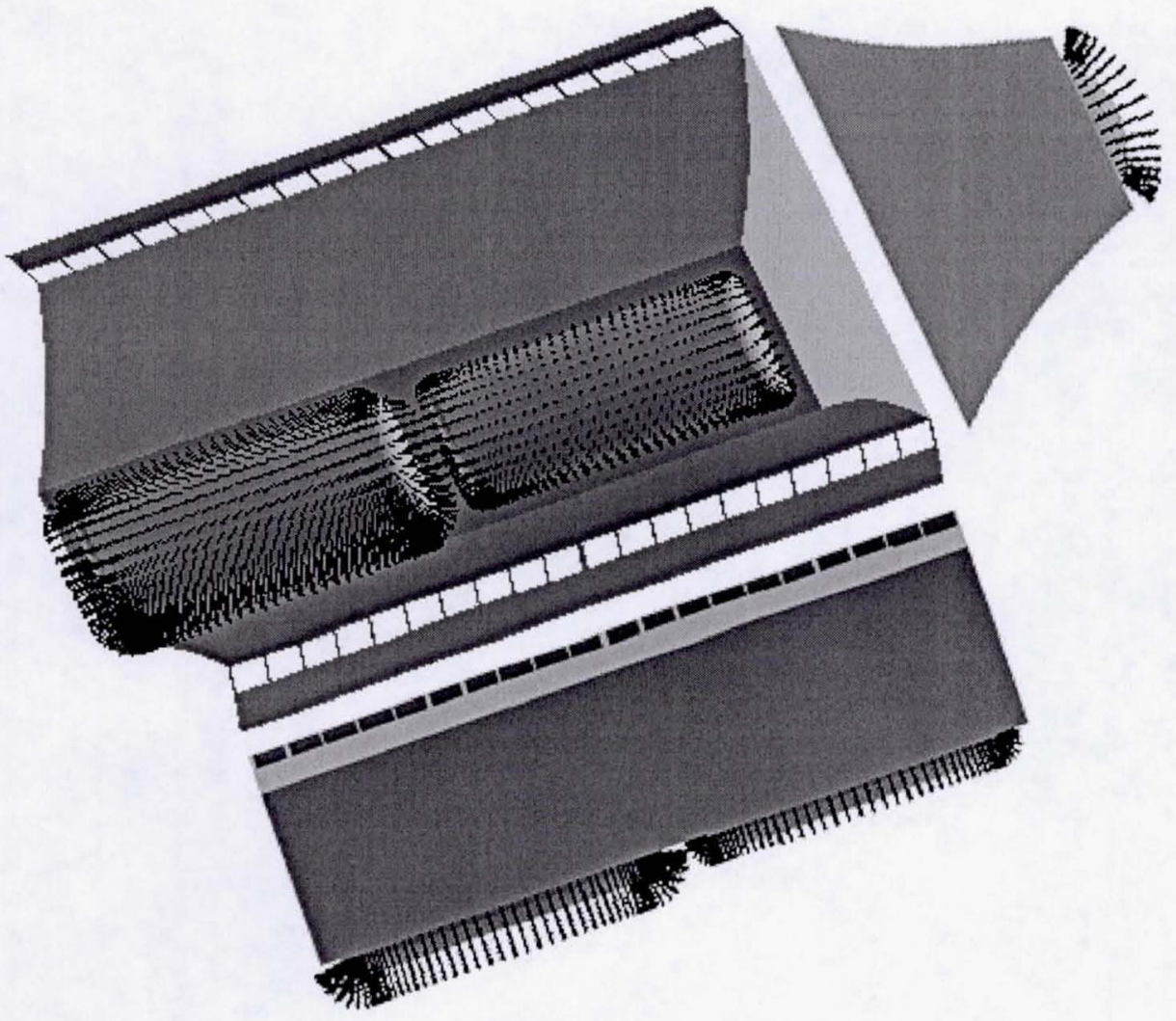

Fig. 2 Computed base-bleed flow vectors at $40 \mathrm{~s}$ of PPO at launch $+30 \mathrm{~s}$ trajectory. 


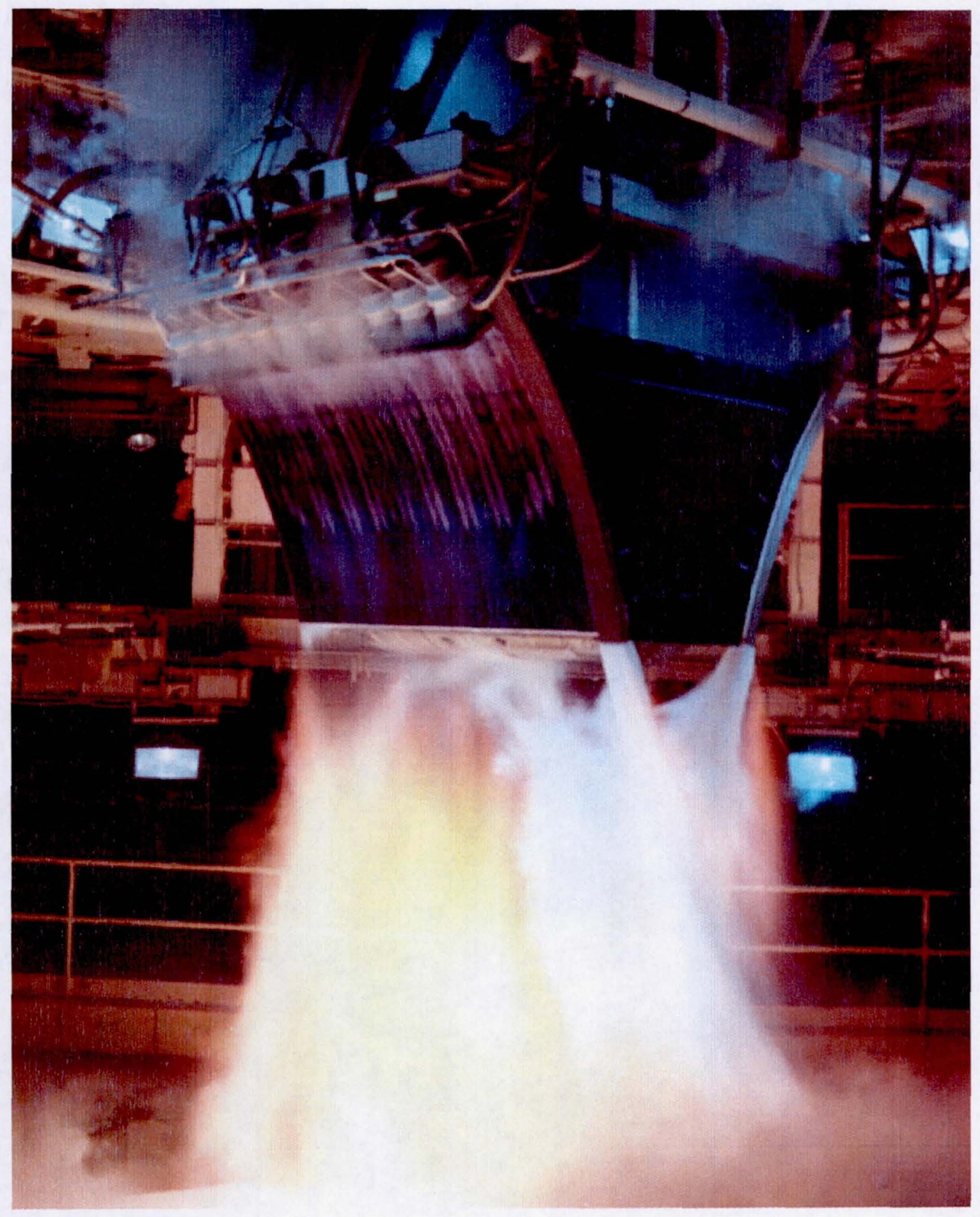

Fig.3 XRS-2200 engine test. 


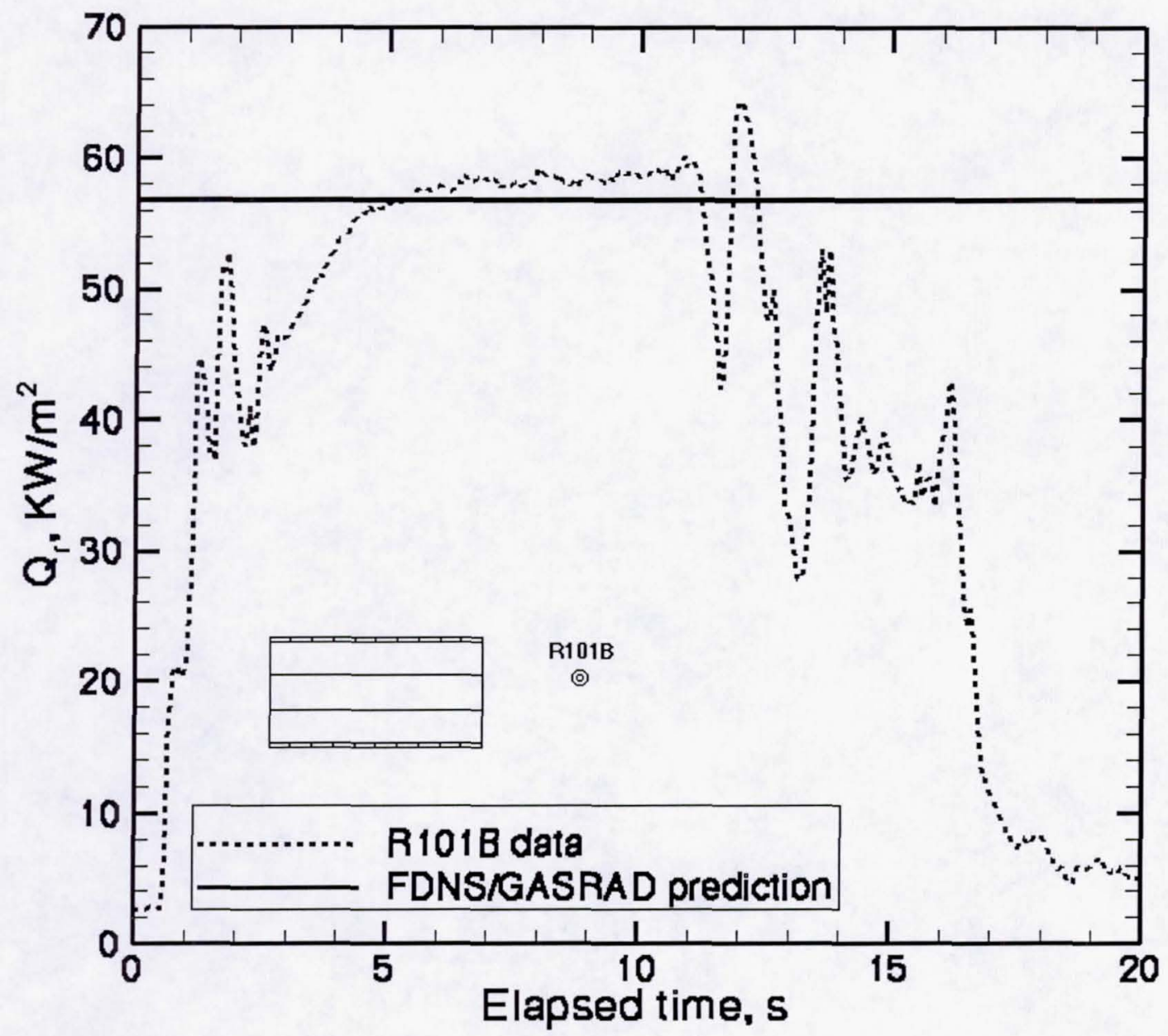

Fig. 4 A comparison of radiative heat fluxes for radiometer R101B. 


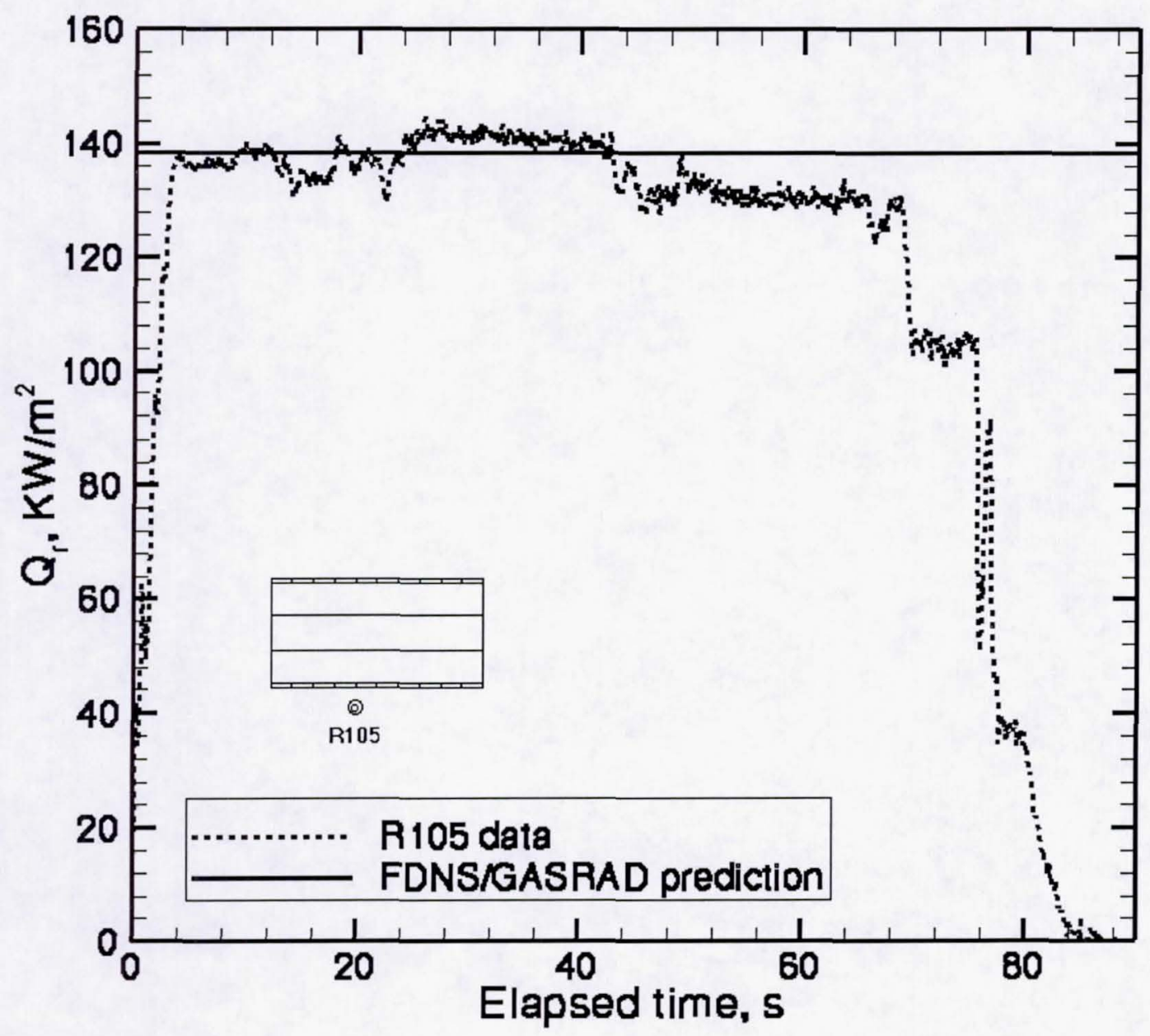

Fig. 5 A comparison of radiative heat fluxes for radiometer R105. 


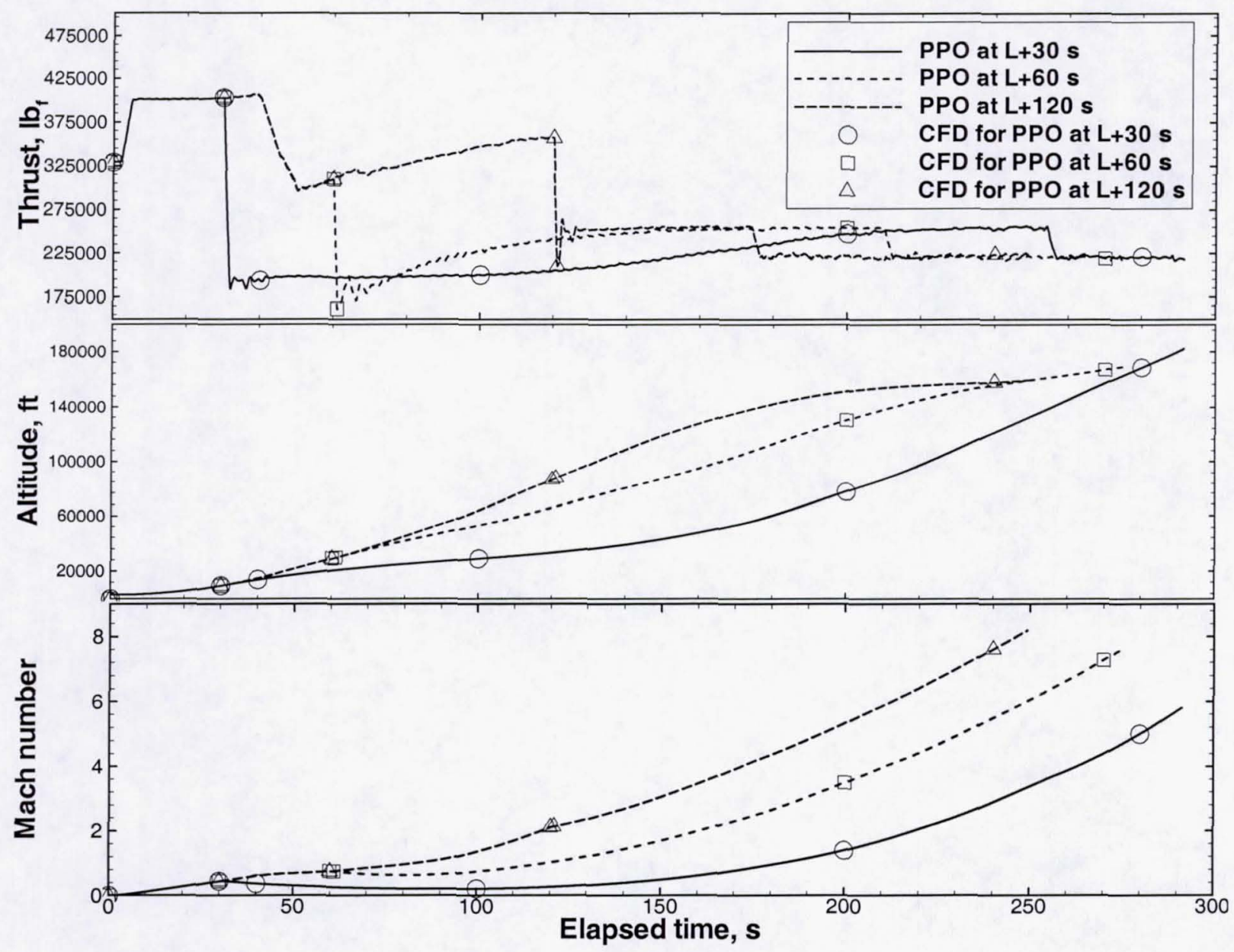

Fig. 6 The thrust, altitude, Mach number profiles and computational points. 


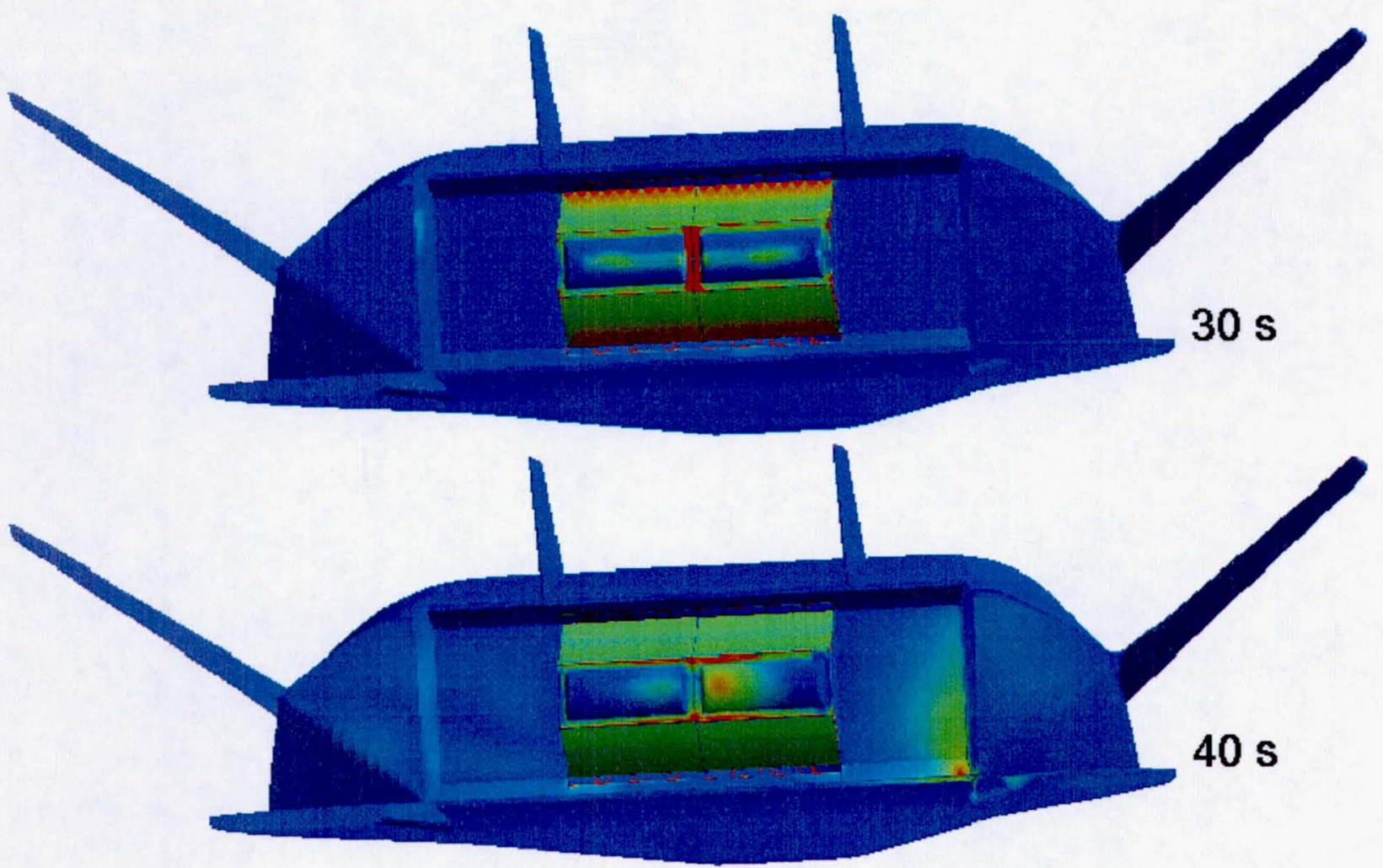

Fig. 7 Convective heat flux contours for power-pack out at launch +30 s trajectory. Color scales: $0-400$ for plug base, $0-9000$ for engine ramp, and $0-60$ for the rest of the body surface. 


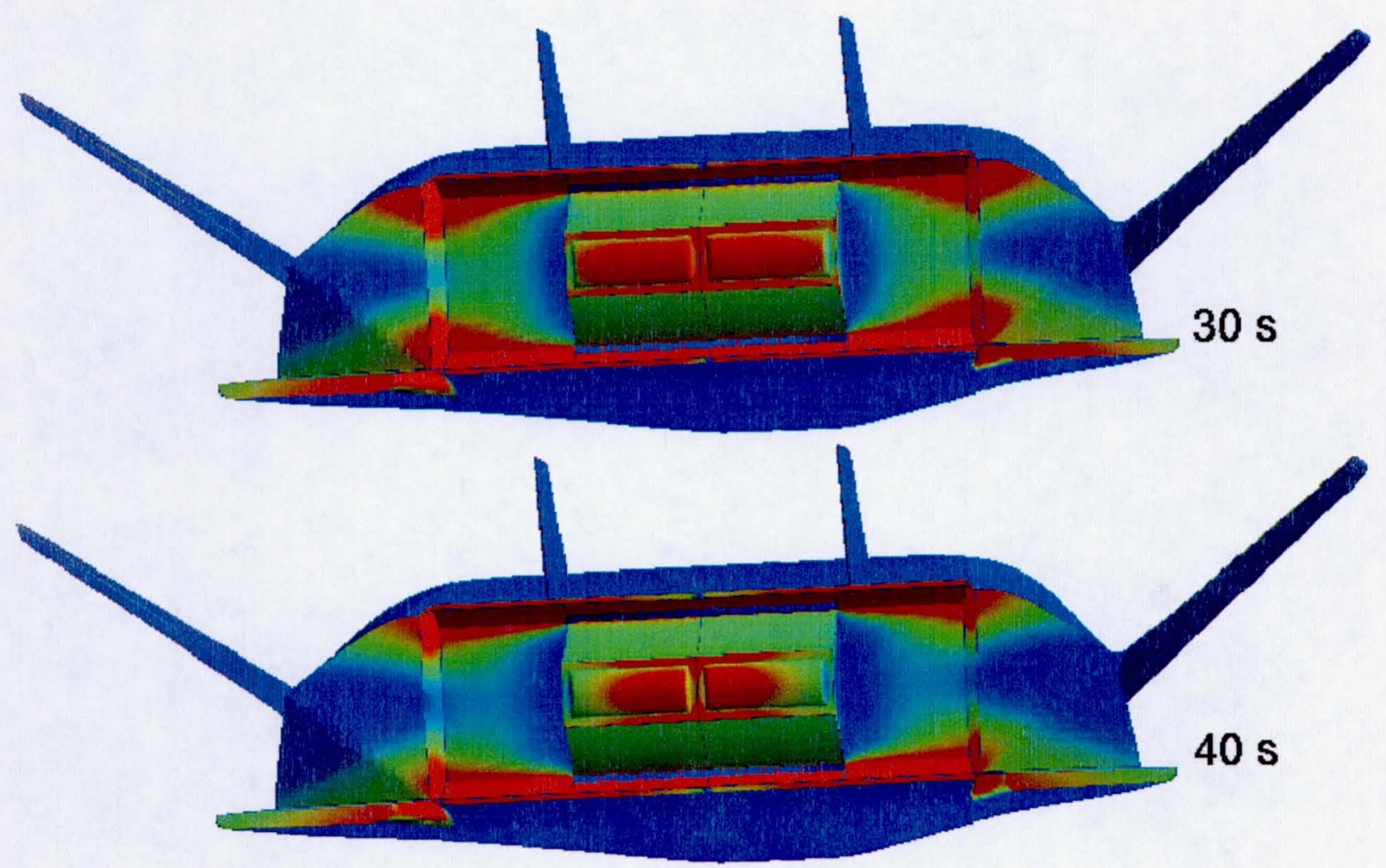

Fig. 8 Radiative heat flux contours for power-pack out at launch +30 s trajectory. Color scales: 0 -600 for plug base, $0-600$ for engine ramp, and $0-170$ for the rest of the body surface. 


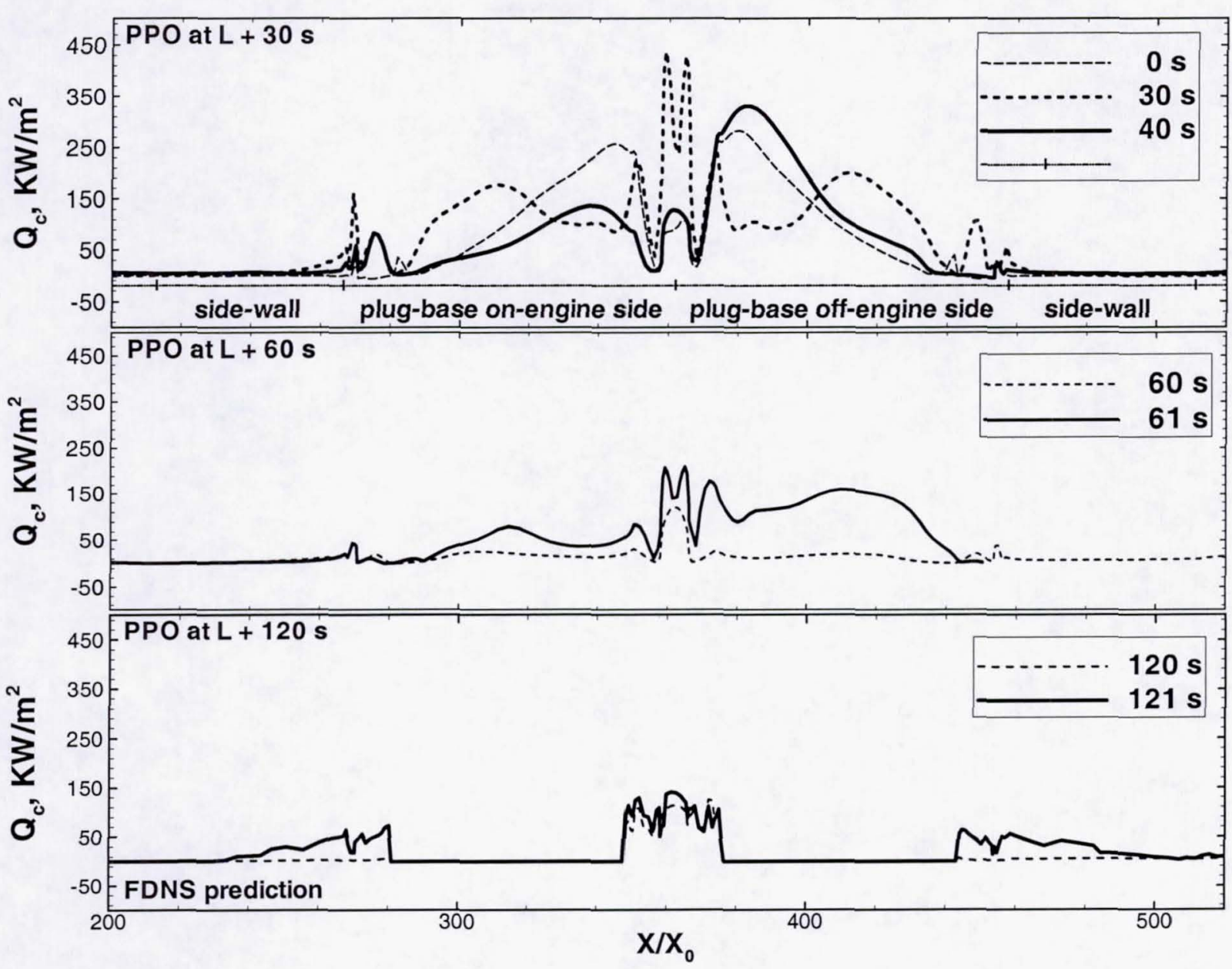

Fig. 9 Effect of power-pack out on base horizontal centerline convective heat fluxes for three power-pack out trajectories. 


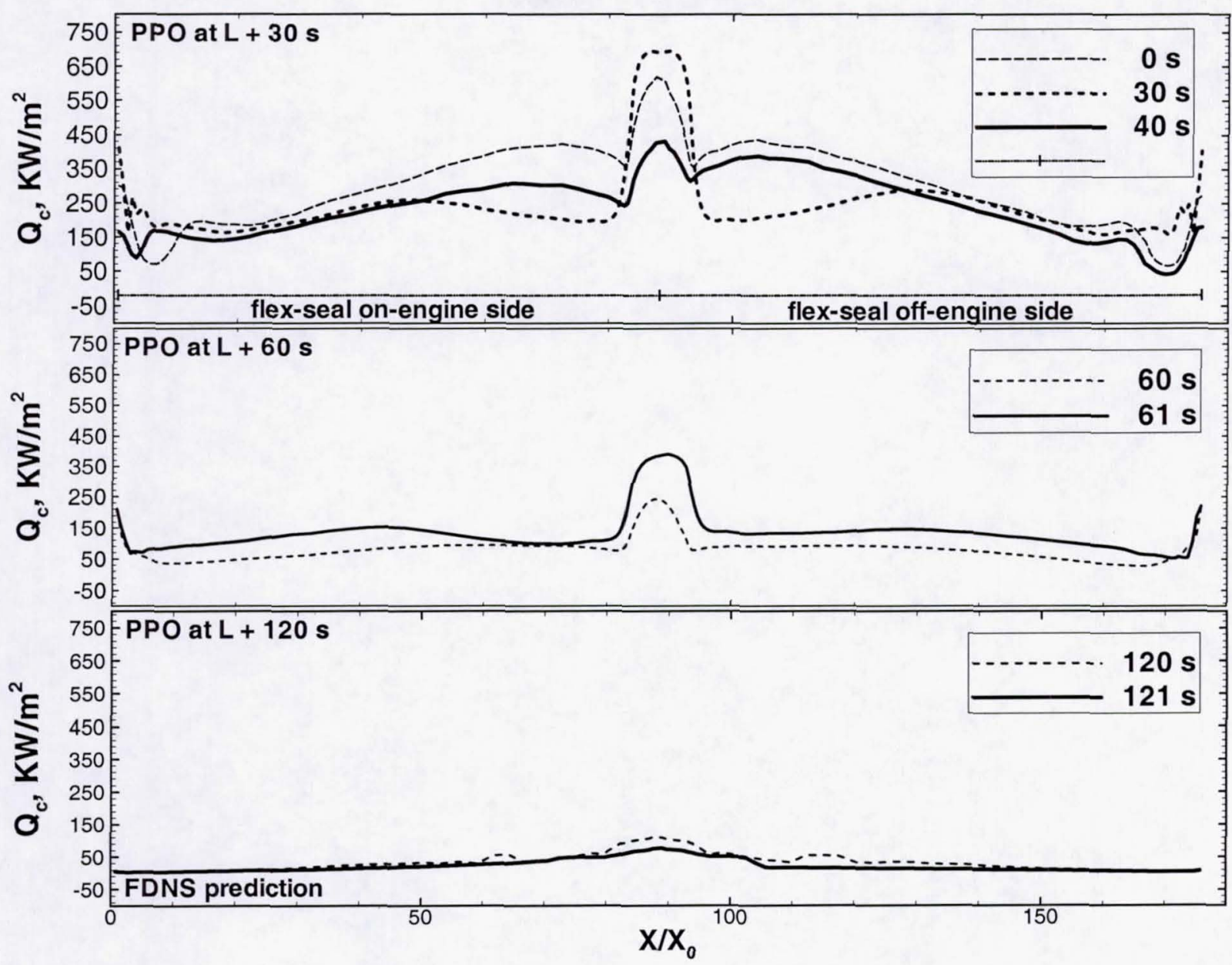

Fig. 10 Effect of power-pack out on lower flex-seal horizontal centerline convective heat fluxes for three power-pack out trajectories. 


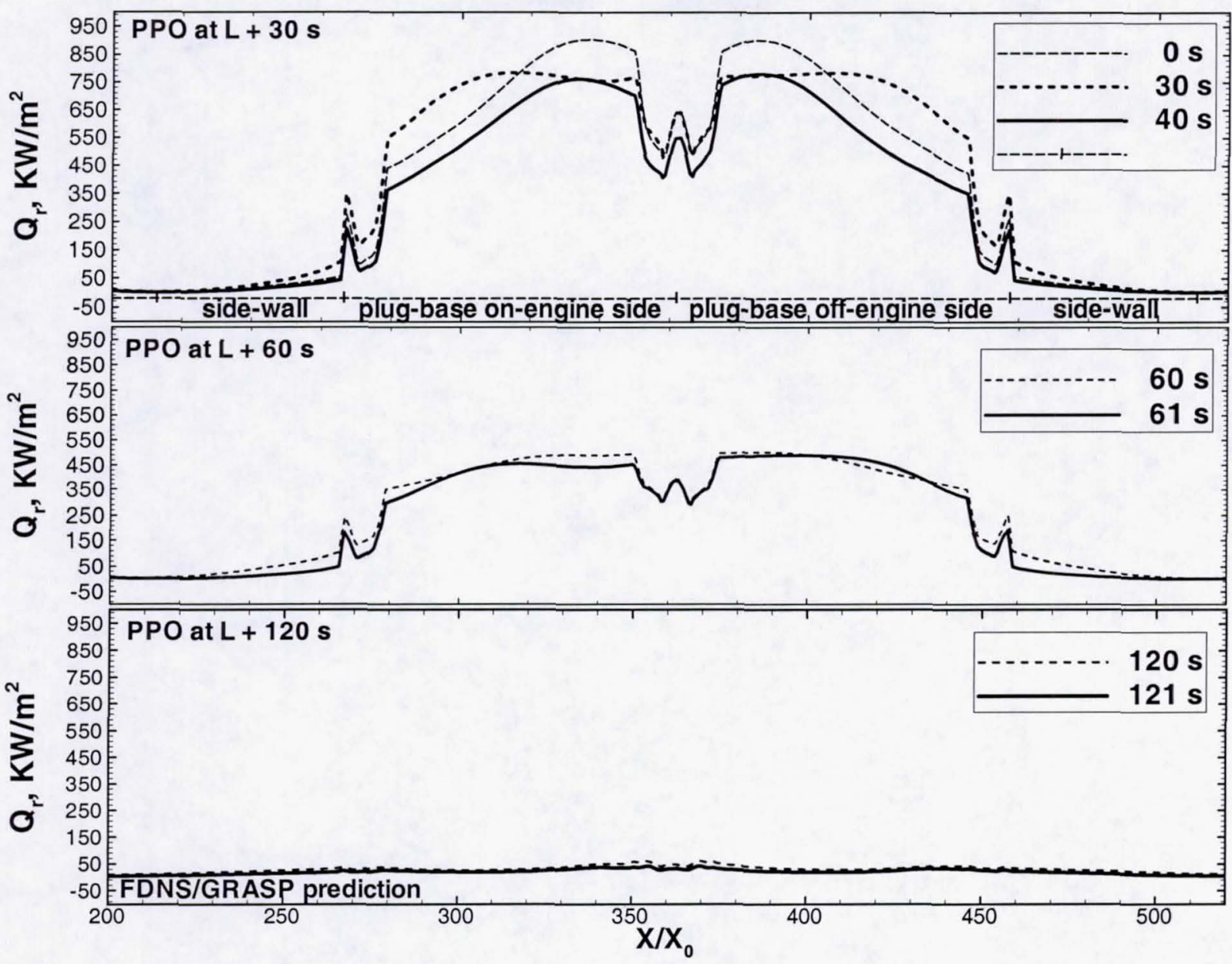

Fig. 11 Effect of power-pack out on base horizontal centerline radiative heat fluxes for three power-pack out trajectories. 


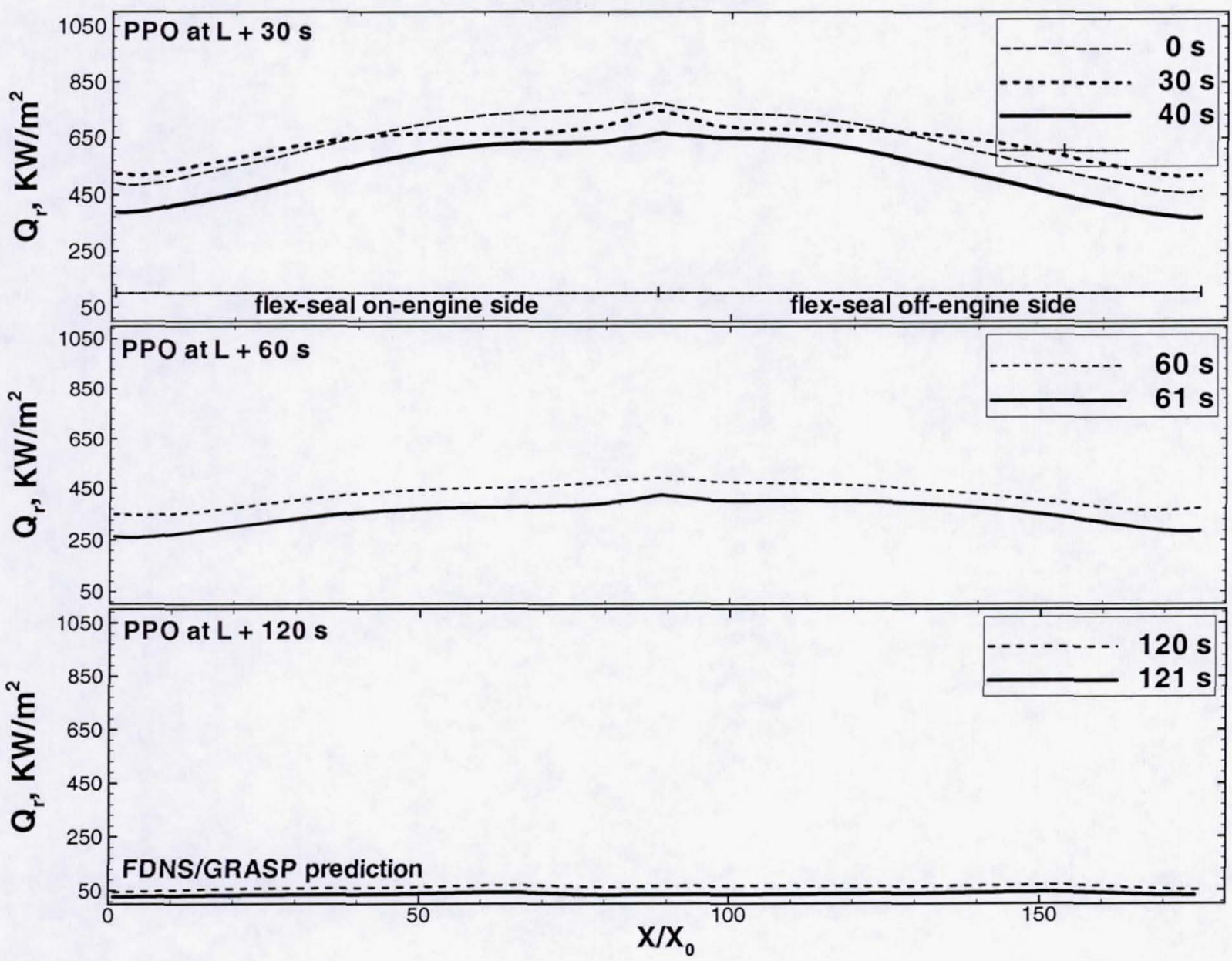

Fig. 12 Effect of power-pack out on lower flex-seal horizontal centerline radiative heat fluxes for three power-pack out trajectories. 